\section{A mulher em situação de cárcere: gênero e processos de significação*}

The woman in the prison: gender and processes of signification

Nathiele Sandi SARAIVA (UFPEL) nathielesaraiva19@gmail.com Luciana Iost VINHAS (UFPEL) lucianavinhas@gmail.com

Recebido em: 30 de jan. de 2019. Aceito em: 04 de jun. de 2019.

*Comunicação apresentada no XXVII Congresso de Iniciação Científica da Universidade Federal de Pelotas, Pelotas-RS, 22 a 26 de outubro de 2018.
SARAIVA, Nathiele Sandi; VINHAS, Luciana Iost. A mulher em situação de cárcere: gênero e processos de significação. Entrepalavras, Fortaleza, v. 9, n. 2, p. 79-92, maio-ago/2019.

Resumo: Com base na Análise de Discurso de tradição pêcheuxtiana, a partir de recortes de dizeres de duas apenadas em regime de privação de liberdade na Penitenciária Feminina Madre Pelletier, localizada na cidade de Porto Alegre (RS), este trabalho objetiva refletir sobre a situação da mulher presa e, também, sobre os discursos existentes em nossa sociedade a respeito de o que é ser mulher e de o que significa ser uma mulher no ambiente carcerário. Observamos, através de marcas linguísticas, principalmente a recorrência de repetições de expressões linguísticas, a reprodução de préconstruídos sobre o papel da mulher na sociedade, a situação da mulher sob regime de privação de liberdade e as relações de gênero dentro do sistema carcerário. Também conseguimos compreender o processo de constituição dos sentidos ao analisar como os préconstruídos afetam a maneira como as mulheres se posicionam como sujeitos.

Palavras-chave: Mulheres. Prisão. Discurso. 
V. 9 (2)

79-92

maio-ago

2019

Abstract: Based on the Discourse Analysis proposed by Michel Pêcheux, the present study aims to discuss the situation of the imprisoned woman, and, also, the existing discourses in our society that concern what it is to be a woman and what it is to be an imprisioned woman. The study analyses the interviews made with two women who were arrested in Madre Pelletier Penitenciary, located in Porto Alegre (RS). We observed, through the examination of the linguistic marks, mainly the recurrence of certain linguistic expressions, the reproduction of preconstructed discourses about the role of the woman in the society, the situation of the woman in the prison, and the gender relations in the prison system. We also were able to explain the process of the constitution of the senses through the analysis of how the preconstructed affects the way women stand as subjects.

Keywords: Women. Prison. Discourse.

\section{Introdução}

Refletir sobre a situação da mulher encarcerada, conforme proposto no presente trabalho, leva-nos a pensar, primeiramente, em alguns pontos importantes, como, por exemplo, o papel da mulher na sociedade, em um processo histórico e social; o funcionamento do sistema carcerário; e, de maneira específica, o sistema carcerário feminino, pois, como dito em Davis (2018, p. 41), "há aspectos em nossa história que precisamos questionar, repensar, e cujo reconhecimento pode nos ajudar a adotar posturas mais complexas e críticas em relação ao presente e ao futuro". Esse movimento de retomar a própria história permite, então, a assunção de uma postura reflexiva crítica frente às obviedades que se apresentam nas discursividades contemporâneas, constituindo quem somos e os sentidos que reproduzimos.

Oliveira (2017, p. 29) realiza uma reflexão sobre a mulher em um processo histórico na nossa sociedade patriarcal que a exclui e oprime desde seu surgimento. A autora diz que:

Desde o nascimento até a morte, a mulher é representada pela sociedade patriarcal como ser incompleto e em constante transformação, pois nascer mulher implica em futuro prémoldado, que estará reforçado por opressões determinadas a partir da forma de vida e classe que ocupa cada mulher, e que arquitetam os cativeiros a que estão submetidas.

Sabemos que a legislação referente ao funcionamento da prisão na formação social brasileira prevê a harmônica integração social do condenado e do internado. A Lei de Execução Penal autoriza o isolamento do indivíduo com o objetivo de habilitá-lo à reintegração à sua vida em liberdade. Trata-se, em última instância, do objetivo da prisão: a ressocialização dos indivíduos condenados pelo Aparelho 
Repressivo de Estado. No entanto, já no senso comum, compreendemos que o funcionamento efetivo da prisão em nossa formação social não se coaduna com aquilo que é preconizado nos documentos oficiais, pois a ressocialização é impossível de ser concretizada em um sistema cujo encarceramento aprimora a criminalidade, ou seja, o ele funciona como um local de reprodução da criminalidade. Além disso, o sistema carcerário opera mais no sentido de excluir os criminosos para proteção dos "cidadãos de bem" do que de promover a educação e a capacitação dos presos para a convivência em sociedade. A prisão existe, em última instância, para proteger quem não está preso, ao invés de ser um investimento no ser humano que não cumpriu com o previsto pela legislação ao cometer um crime, considerando que todos os cidadãos inscritos na democracia moderna são sujeitos-de-direito.

Pensando sobre a história das mulheres, percebe-se que a mulher cidadã não é tratada da mesma maneira que o homem cidadão, visto que, para tornarem-se cidadãs, as mulheres tiveram que lutar muito para garantirem o direito do voto no século XIX com o movimento sufragista. Este é somente um dos tantos aspectos que diferenciam as mulheres dos homens, cujos efeitos ainda observamos até o momento presente. Portanto, as mulheres, àquela época, não eram vistas como dignas de exercerem direitos como os homens; logo, ao cometer um crime, uma mulher, já que não possuía direitos e não era vista como uma cidadã, estava em posição de exclusão ainda mais frágil se comparada com um homem criminoso.

O mesmo acontecia com o movimento pelos direitos civis nas décadas de 1950 e 1960 nos Estados Unidos, que lutava pelo direito dos negros ao voto. Percebe-se que há, além de uma diferença de gênero, uma diferença racial: as mulheres brancas garantiram o direito ao voto no século XIX, enquanto as mulheres negras só garantiram o direito ao voto 75 anos depois. Desse modo, as diferenças de acesso a direitos se materializam no gênero, na raça e na classe social.

Antes da luta pelo direito do voto feminino e racial, na história, as mulheres que cometiam crimes não podiam ir à prisão, por isso o Estado criava outros métodos de punição. Na Idade Média, por exemplo, o discurso jurídico unia-se aos discursos médico e teológico. As mulheres que estavam à margem do que a sociedade considerava "normal" eram diagnosticadas com doenças mentais, de acordo com o discurso médico, ou as dominadas por forças sobrenaturais que seguiam o mal, pelo discurso teológico. Conforme Oliveira (2017, p. 71): 
V. 9 (2)

79-92

maio-ago

2019

O comportamento das mulheres é compreendido em função de uma dimensão de anormalidade, ou seja, tem-se uma percepção científica em relação à criminologia do gênero feminino que segue a dicotomia bondade/maldade, pureza/pecado, passividade/ agressividade, submissão/insurreição para elaborar o papel social da mulher pautando-se em crenças escritas por homens.

O Estado atua com duas formas de controle social: o informal, com a família, a escola e a profissão, compreendido por Althusser como Aparelhos Ideológicos de Estado, e o controle formal, com os agentes de poder, como polícia, justiça e a administração penitenciária, agrupados no que Althusser chamou de Aparelho Repressivo de Estado (ALTHUSSER, 2008). A mulher que não segue os padrões da sociedade sofre mais discriminação do que o homem, por conta de seu histórico social.

Ainda refletindo sobre o período da Idade Média, período este que marcou a história da mulher na sociedade, podemos citar o livro de 1484, Martelo das Bruxas, que ficou conhecido como primeiro discurso criminológico das mulheres, pois tratava as mulheres que estavam à margem do que a sociedade julgava certo como bruxas e como ameaças à humanidade, argumento que era utilizado para justificar a brutalidade, a tortura que as instituições de poder aplicavam nas suspeitas durante as investigações (OLIVEIRA, 2017). A maneira como as mulheres tratadas como feiticeiras foram punidas publicamente foi um acontecimento crucial para a figura da mulher na sociedade e incentivou diversas mulheres a seguirem o modelo de mulher imposto pelo Estado.

Por isso, ainda hoje, existe uma tentativa do Estado de controlar os corpos e as escolhas das mulheres que, ao longo da história, foram, e ainda são, oprimidas e excluídas pela sociedade patriarcal que se identifica e reproduz um discurso machista, e, por conta de uma questão histórica, obviamente, há também uma diferença de gênero dentro do sistema carcerário que nasce de um discurso machista préconstruído e naturalizado em nossa sociedade. O discurso machista, então, parece obter uma posição hegemônica em nossa formação social.

O nosso objetivo principal é refletir sobre a situação da mulher presa, mais especificamente, sobre o que significa ser mulher no ambiente carcerário. Esta pesquisa se desenvolve pela análise de dizeres de duas apenadas da Penitenciária Feminina Madre Pelletier. Para tanto, lançamos mão do arcabouço teórico da Análise de Discurso de tradição francesa, conforme proposta por Michel Pêcheux e seu grupo de estudiosos na França, na segunda metade do século XX. Apresentamos, a seguir, os principais pressupostos teórico-analíticos que guiaram a presente pesquisa. 


\section{Referencial teórico}

Conforme Michel Pêcheux, entende-se o discurso como o efeito de sentido entre interlocutores num processo histórico e social, que se materializa na linguagem, permitindo-nos observar as relações existentes entre a ideologia e a língua. Com base nisso, o presente trabalho tem como objetivo analisar recortes de entrevistas de duas apenadas da Penitenciária Feminina Madre Pelletier, observando marcas linguísticas presentes nos dizeres dessas mulheres que nos levam a identificar relações entre o funcionamento da ideologia e do inconsciente.

A ideologia constitui os sujeitos por meio da sua materialização no discurso e, por conseguinte, na língua; ela se materializa na linguagem, em um processo histórico, segundo Orlandi (2007), possuindo, portanto, uma forma de existência material. Através das respostas das apenadas, observando o princípio da regularidade discursiva, podemos detectar elementos referentes ao funcionamento de uma identificação e, também, de uma desidentificação com o discurso machista no ambiente carcerário que influenciam na maneira como as mesmas, enquanto mulheres, em regime de privação de liberdade, criam um imaginário de si.

Foram identificadas, através destas marcas linguísticas, a reprodução de pré-construído sobre o papel da mulher na sociedade, a situação de uma mulher no cárcere e as relações de gênero dentro do sistema carcerário. Falaremos, assim, sobre como o pré-construído afeta a maneira como essas mulheres se constituem como sujeitos. A noção de pré-construído, de acordo com Pêcheux (2009), diz respeito àquilo que foi dito antes, em outro lugar, independentemente. Sendo assim, entendemos que o discurso das apenadas sobre a situação de cárcere se baseia em discurso naturalizado e aceito, já existente em nossa sociedade, e, por isso, determina a maneira como elas se imaginam como sujeitos. A forma como as apenadas se representam, ou seja, a imagem que elas constroem delas mesmas é determinada por um discurso dominante vinculado a um saber que todo mundo sabe, o que o caracteriza como pré-construído. Os imaginários de mulher e de mulher presa são convocados como imagens naturais dentro da formação social capitalista. Essas formações imaginárias, então, atuam na determinação das subjetividades.

Pretende-se, a partir disso, refletir sobre o processo de interpelação ideológica a partir da posição dominante ocupada por 
V. 9 (2)

79-92

maio-ago

2019

uma formação discursiva machista. Sendo assim, percebe-se que o funcionamento do pré-construído determina a forma como elas se representam, imaginariamente, na sociedade, sendo o sujeito do discurso não um sujeito empírico, mas uma posição a partir da qual se fala, influenciado de forma não consciente pela ideologia. Essas posições atribuídas ao sujeito em $\mathrm{AD}$ estão relacionadas a representações imaginárias que, de acordo com Silva (2010, p. 18), "resultam de processos discursivos anteriores que deixaram de funcionar, mas continuam determinando o processo discursivo em foco".

Focalizamos nas noções de imaginário e de pré-construído que, na nossa proposta, estão em estreita relação, posto que a forma como o sujeito se representa vem de uma determinação anterior, já-sabida. O pré-construído determina o discurso dos sujeitos na reprodução de discursos já existentes, tidos como naturalizados, como visto em Pêcheux (1997, p. 77): "o que funciona nos processos discursivos é uma série de formações imaginárias que designam o lugar que A e B atribuem cada um a si e ao outro, a imagem que eles se fazem de seu próprio lugar e do lugar do outro". Nesse sentido, a imagem que o sujeito tem de si determina os processos de significação e, de forma inalienável, de subjetivação.

Segundo Orlandi (2003, p. 15), o dispositivo teórico-analítico, em análise do discurso, visa a "compreender a língua fazendo sentido, enquanto trabalho simbólico, parte do trabalho geral social, constitutivo do homem e da sua história". Então, a partir da linguagem, o ser humano se constitui como sujeito social, e é através da língua fazendo sentido que percebemos a interpelação da ideologia na maneira como o sujeito se identifica. Desse modo, percebe-se que a ideologia se materializa na língua pela existência do interdiscurso, isto é, discursos já existentes que circulam em nossa sociedade e que são atualizados quando da sua colocação em circulação. A língua torna-se materialidade; ela não é pura e literal, reprodutora de um sentido pronto e acabado.

A concepção de subjetividade da Análise de Discurso considera, além da determinação pela ideologia, a determinação pelo inconsciente. Esse duplo atravessamento, que opera na constituição de um sujeito cindido, traz efeitos no processo de produção, reprodução e transformação dos sentidos (e dos próprios sujeitos). O inconsciente atua na possibilidade de o sujeito reproduzir aquilo que não está previsto pela formação discursiva que o determina ideologicamente. O processo de interpelação ideológica é, portanto, um processo com falhas, posto que o sujeito é dotado de inconsciente. 
Neste dispositivo teórico-analítico, o sujeito está submetido ao inconsciente e, também, às circunstâncias sociais que o atravessam. Assim, o sujeito ocupa uma posição em relação à ideologia, identificando-se com determinada formação discursiva, a qual o faz dizer o que diz. O sujeito discursivo é pensado a partir de posições determinadas pelas relações de força dando os sentidos do discurso de quem produz e de quem lê.

A partir disso, para a análise desenvolvida neste trabalho, como já dito, atentamo-nos, especialmente, para a noção de pré-construído. Também trabalhamos com a noção de formações imaginárias, pois se sabe que há um discurso pré-construído sobre a mulher criminosa que não só determina sua posição-sujeito na sociedade como também afeta as formações imaginárias, ou seja, o imaginário construído sobre si mesmas. No entanto, sabendo que o imaginário pode, conforme Silva (2010), conter falhas devido à existência do real, procuraremos também as manifestações linguísticas que nos levam a esse lugar, que, em AD, é onde há a contradição entre a ideologia e a história na língua. Em vista disso, observaremos o processo de interpelação ideológica através de marcas linguísticas que nos permitam perceber a existência da interpelação e do processo histórico-social que as levam a identificarse com determinada formação discursiva, porque, como observa Orlandi (2003, p. 27), a posição do analista deve ser relativizada em face da interpretação, não sendo, portanto, neutra: "é preciso que ele atravesse o efeito da transparência da linguagem, da literalidade do sentido e da onipotência dos sujeitos".

\section{Análise: da escolha do corpus às apenadas}

Para a delimitação do corpus, partimos da proposta de Ernst (2009) sobre os conceitos de Falta, Excesso e Estranhamento. Esses conceitos abarcam três maneiras pelas quais o analista de discurso pode se aproximar de seu arquivo, procurando marcas linguísticas que apontem para algo que falta, algo que excede ou algo que causa estranheza no texto sob análise. A falta, o excesso e o estranhamento podem ser produtivos, portanto, no trabalho de se compreender a forma como a ideologia se materializa na língua e produz/faz circular efeitos de sentidos. Conforme a autora,

Tais conceitos podem e devem abrigar incontáveis modos do dizer e do não-dizer. Assim, numa dada conjuntura histórica frente a um dado acontecimento, aquilo que é dito demais, aquilo que é dito de menos e aquilo que parece não caber ser 
V. 9 (2)

79-92

maio-ago

2019 dito num dado discurso, constitui-se numa via possível, mesmo que preliminar e genérica, de identificação de elementos a partir dos quais poderão se desenvolver os procedimentos de análise do corpus. Esse parece ser o rumo tomado por vários analistas (ERNST, 2009, p.2).

O primeiro recorte selecionado para análise consta da entrevista de uma das apenadas que, naquele momento, tinha 35 anos e estava em regime penitenciário há seis anos, faltando ainda sete anos para o cumprimento da pena à qual foi sentenciada por um assalto a banco e um homicídio. Estava presa pela quarta vez. Tinha três filhos, sendo o mais novo nascido na prisão, pois ela estava grávida de um mês quando foi presa. O marido a deixou quando ela foi presa e a família não a visitava. A apenada confessou que às vezes recebe visita dos filhos; no entanto, preferia ficar sozinha, pois achava errado submeter a família ao ambiente carcerário. O recorte consta na Sequência Discursiva (SD) 01.

SD01: não... meu marido... depois di dois anos que eu tava aqui ele arrumô otra companhera pra é vê ele que é normal né... noventa e nove por cento dos homens que as mulher vêm presa eles arrumam otra né... ih aí ele arrumô otra companhera... ih foi tranquilo assim... eu já esperava por isso pelo fato de eu saber que eu tinha que ficar aqui muito tempo eu já esperava tudo isso... tudo o que acontece eu já espero né então eu já esperava por isso... ih agora eu tô sozinha assim... quem vive sozinha é que vive melhor

Percebemos, na fala da apenada, a ocorrência de repetições das expressões né e já esperava/já espero, destacadas na sequência, que nos apontam para os sentidos relacionados ao processo de interpelação ideológica influenciada pelo discurso machista que circula dentro do sistema carcerário. As repetições nos remetem ao conceito de Excesso proposto por Ernst (2009, p. 04). Conforme a autora, o excesso concerne a uma:

estratégia discursiva que se caracteriza por aquilo que está demasiadamente presente no discurso. Consiste: 1) no uso de incisas, considerado na gramática como um acréscimo contingente (cf. Haroche, 1992), de intensificadores ou na repetição de palavras ou expressões e orações. Tais usos, na perspectiva aqui adotada, constituem-se em "acréscimo necessário" ao sujeito que visa garantir a estabilização de determinados efeitos de sentido em vista da iminência (e perigo) de outros a esses se sobreporem. 
No que diz respeito à expressão né, compreendemos que é muito empregada na língua portuguesa oralizada, a qual convoca uma resposta afirmativa, uma concordância por parte do interlocutor, como se ambos já soubessem sobre a "verdade" daquilo de que se está falando; desse modo, na sequência discursiva analisada, o uso desta expressão nos remete ao conceito de pré-construído. Quando a apenada usa a expressão né no final das sequências enquanto explica o que geralmente acontece com os maridos das mulheres que vão presas, ela acredita que seu interlocutor esteja ciente deste processo; por isso, ao final das sequências, usa uma expressão que indica a espera de uma confirmação, como se estivesse falando algo que todo mundo sabe.

O pré-construído referente à figura da mulher criminosa e da diferença de gênero circula de maneira tão naturalizada que a apenada, como sujeito interpelado ideologicamente a partir de sua posição sujeito na sociedade, mulher criminosa, inconscientemente reproduz o discurso de que a mulher que está sob regime de privação de liberdade está destinada a não receber apoio de seus companheiros. Tal situação é o contrário do que geralmente acontece quando os homens vão presos, pois as esposas/companheiras, e, inclusive, as mães, tendem a continuar apoiando-os, fazendo visitas regulares, durante o período de cárcere.

Se usar uma expressão que remete a uma resposta afirmativa, como a expressão né nos remete ao conceito de pré-construído, a recorrência de uma outra expressão destacada, já esperava/já espero, nos remete ao conceito de imaginário, sendo que nele, conforme Silva (2010), devido à particular articulação existente no quadro epistemológico da $\mathrm{AD}$, coexistem duas acepções de imaginário: é algo que advém do social, da forma histórica da ideologia nas formações sociais e é um dos registros da estrutura psíquica. O advérbio já antes do verbo esperava nos remete à ideia de que a apenada, em função de sua posição-sujeito na formação social, sabia que, quando fosse presa, o marido a abandonaria e ficaria com outra. Por conta de sua condição e do pré-construído, a presa se imagina, e, com isso, pressupõe que seu interlocutor também a imagine desta maneira, como uma mulher que, por ser criminosa e estar à margem da sociedade, não merece ter seu marido ao lado para acompanhá-la durante o processo e, por isso, aceita esta situação como se fosse algo normal. A solidão é, portanto, característica das mulheres em situação de encarceramento.

Segundo Oliveira (2017, p. 44): 
V. 9 (2)

79-92

maio-ago

2019
Os traços de personalidade adquiridos pelas mulheres ao longo de todo o processo de socialização fazem com que todas acreditem, pelo menos em um primeiro momento, que não são capazes, pois foram ensinadas que a razão não lhes pertence, condicionando-as, via de regra, a não terem confianças em si mesmas, fato que as impede de lutar vigorosamente para mudar a sua condição de inferioridade.

Ocorre, a partir da análise do recorte apresentado na SD01, a reprodução de saberes organizados por uma formação discursiva machista, tida como discurso dominante e, portanto, de onde são reproduzidos pré-construídos, que orientam a forma como as mulheres se subjetivam. A partir dessa subjetivação, ou seja, da forma como os sujeitos atribuem sentido, a apenada não se desvincula de uma posição naturalizada socialmente, predominante na nossa formação social, sendo, portanto, vinculada a algo que todo mundo sabe.

O segundo recorte selecionado para a presente análise vem da entrevista de uma apenada que estava na cadeia pela segunda vez, era solteira e tinha dois filhos. Estava presa há um ano e nove meses e teve a pena diminuída por contribuição de trabalho na cadeia. Ela conta que o único membro da família que vai visitá-la é a mãe e reflete sobre o sistema carcerário e a diferença de tratamento entre o homem preso e a mulher presa.

SD02: porqui no momento qui entra naquele portão aqui dentro... acabô tudo... amigos não existi mais... família... praticamente é poca... família qui luta tá ali junto pra vim visita... tá passando por revista.. é poucas na família... como a genti diz na cadeia dos homi chega dobrá a fila... dá volta na cadeia... na cadeia das mulher tu conta nos dedo as pessoa qui tão ali... qui é o quê? SEMPRE a mãe... o marido... NUNCA... né... AH ela tá presa azar dela... o problema é dela qui tá ali... ela cometeu o crime não fui eu tô na rua... tá com otras né... então né::: tem qui assim tê a cabeça firme né... mantê a menti... ih cuidá dos filho... cuidá da família ih... sigui em frenti... levanta a cabeça né... ih mostrar qui as mulheres né... também tem a dignidade di tá né... a frenti di tudo... a frenti não é só os home... não é quere sê dependenti dos homi... ah não vô trabalha porqui os homi vão tê qui fazê... NÃO... as mulher também TEM esse podê TRABALHÁ pra construi a família SÊ A CHEfi da casa 
No dizer da apenada, percebe-se uma reflexão sobre as relações de força dentro do sistema carcerário quando ela compara as filas para visita na cadeia dos homens com as filas para as cadeias das mulheres, além de uma identificação com a formação discursiva feminista, quando fala sobre os espaços e posições que as mulheres devem ocupar na sociedade.

Linguisticamente, temos, mais uma vez, a recorrência da expressão né, que remete ao conceito de excesso; no entanto, diferentemente do emprego da palavra no dizer da primeira apenada, no presente recorte discursivo, a expressão né convoca o sentido de que a apenada não se identifica com o discurso machista e, sim, com os ideais feministas, pois acredita que, mesmo havendo uma diferença de gênero na sociedade, as mulheres devem continuar lutando para ocupar os espaços.

Além das repetições, o uso dos advérbios sempre e nunca para se referir aos papéis de mãe e de marido no cárcere feminino ganha ênfase no discurso e nos remete novamente à noção de pré-construído nas relações de gênero no âmbito social, pois não há acompanhamento dos maridos no processo, como visto na entrevista da primeira apenada.

Com isso, podemos constatar o pressuposto básico da Análise de Discurso de que o sentido não é preso à língua; apesar de as duas sequências apresentarem o excesso como elemento material que aponta para o funcionamento da ideologia, as formações discursivas a partir da qual as duas sequências operam são diferentes, e, mais do que isso, antagônicas. Sendo assim, o excesso opera, de um lado, na reprodução de saberes da formação discursiva machista, e, de outro, na reprodução de saberes vinculados à formação discursiva feminista. Os efeitos de sentido instaurados, então, são diferentes, mas o mecanismo linguístico empregado pelas apenadas no processo de dar corpo à ideologia é o mesmo.

\section{Considerações finais}

Como visto em Oliveira (2017), há uma tradição cultural, influenciada e reproduzida pelas estruturas de poder e pelos agentes envolvidos na trama de relações sociais que comprova que a relação de gênero não é dada e, sim, construída. A partir de uma recapitulação histórica, comentamos que as mulheres não eram vistas como cidadãs e não exerciam o direito ao voto. A luta pelos direitos civis das mulheres, através do movimento sufragista, ganhou resultados somente a partir do século XIX. As mulheres da Nova Zelândia foram as primeiras 
V. 9 (2)

79-92

maio-ago

2019

mulheres do mundo a conquistarem o direito de irem às urnas, em 1893, enquanto que, no Brasil, apenas no ano de 1932 foi concedido o direito ao voto para as mulheres brasileiras. Além da diferença temporal entre a conquista do direito ao voto em diferentes países do mundo, há outro fator importante de se ressaltar: esta conquista foi concedida apenas às mulheres brancas; as mulheres negras conseguiram o direito ao voto somente 75 anos depois, após a luta dos direitos civis iniciada em 1955 nos EUA, que garantiram o direito ao voto para pessoas negras 10 anos depois, em 1965.

Durante a história, sempre houve opressão e tentativa de controle sobre as mulheres. Os discursos médico e teológico, junto com o discurso jurídico, rotulam as mulheres que estavam à margem do que a sociedade acreditava ser "correto" e, na Idade Média, estas mulheres foram punidas publicamente de acordo com o julgamento destes discursos.

As mulheres enfrentam a opressão ao longo da história e, apesar de, com muita luta, terem conseguido algumas conquistas com o passar dos anos, ainda vivemos em uma sociedade machista e patriarcal que reflete na maneira como se imaginam e como imaginam serem vistas de acordo com o papel que a mulher deve exercer.

Com os dizeres das apenadas, podemos perceber, na SD01, a interpelação ideológica através do excesso de expressões que mostram uma identificação com um discurso machista. Existe um pré-construído sobre a figura da mulher que comete um crime: se cometeu, deve arcar com as consequências sozinha, sem um companheiro. Assim como também existe um pré-construído sobre a mulher companheira de um criminoso submetido ao cárcere, que diz que ela deve continuar ao lado dele o apoiando durante o processo. O mesmo se confirma na $\mathrm{SD} 2$, com o uso dos advérbios sempre e nunca no dizer da apenada ao falar sobre as visitas nas cadeias femininas. A mãe é o único familiar que frequenta a cadeia, enquanto que o marido não o faz, além de abandonar a mulher por outras na rua.

Esse discurso, sócio-historicamente naturalizado, age no processo de interpelação/identificação das mulheres, mesmo aquelas que se encontram em posição dominada na formação social, por serem apenadas pobres e negras, na maioria das vezes. Conforme visto em Pêcheux (1997), as diversas formações resultam de processos anteriores que deixaram de funcionar, mas que deram nascimento às tomadas de posição implícitas que asseguram a possibilidade de o processo discursivo em foco tomar lugar. 
Com base na análise desenvolvida, percebe-se a atuação de formações discursivas a partir das quais ocorre a subjetivação dessas mulheres encarceradas, sendo uma formação discursiva relacionada ao machismo e outra formação discursiva vinculada ao feminismo. Consideramos que o saber pré-construído advém da formação discursiva machista, compreendida como a dominante em nossa formação social atual.

Assim, trazemos Oliveira (2017):

Dar voz às detentas é necessário para conhecer a realidade do sistema judiciário criminal e, ao mesmo tempo, conhecer os sentimentos e as perdas que ali ocorrem, as resignações das vidas de cada uma, as formas como encaram seus dias de cinza, suas dores e suas pretensões.

Consideramos, assim, a importância de dar voz às minorias que constituem a formação social brasileira, especialmente em momentos de exclusão no nosso Estado Democrático de Direito determinado pela formação social capitalista neoliberal.

\section{Referências Bibliográficas}

ALTHUSSER, Louis. Sobre a reprodução. Tradução de Guilherme João de Freitas Teixeira. 2.ed. Petrópolis: Vozes, 2008.

DAVIS, Angela. Estarão as prisões obsoletas? Tradução de Marina Vargas. Rio de Janeiro: Difel, 2018.

ERNST, Aracy Graça. A falta, o excesso e o estranhamento na constituição/ interpretação do corpus discursivo. In: SEMINÁRIO DE ESTUDOS EM ANÁLISE DO DISCURSO, 4., 2009, Porto Alegre, RS. Anais do IV SEAD - Seminário de Estudos em Análise do Discurso. Porto Alegre: UFRGS, 2009. Disponível em: <http://anaisdosead.com.br/4SEAD/SIMPOSIOS/AracyErnstPereira.pdf >. Acesso em: 18 dezembro 2018.

OLIVEIRA, Camila Belinaso. A mulher em situação de cárcere: uma análise à luz da criminologia feminista ao papel social da mulher condicionado pelo patriarcado. Porto Alegre: Editora FI, 2017.

ORLANDI, Eni Puccinelli. Análise de Discurso: Princípios e Procedimentos. 5.ed. Campinas: Pontes, 2003.

Discurso e Leitura. São Paulo: Cortez, 2007.

PÊCHEUX, Michel. Análise Automática do Discurso (AAD-69). In: GADET, Françoise; HAK, Tony. (Orgs.) Por uma análise automática do discurso: Uma introdução à obra de Michel Pêcheux. Tradução de Bethania S. Mariani [et al.] 3.ed. Campinas: Editora da UNICAMP, 1997.

Semântica e discurso: uma crítica à afirmação do óbvio. Tradução de Eni Orlandi et al. 4.ed. Campinas: Editora da UNICAMP, 2009. 
v. 9 (2)

79-92 maio-ago 2019

SAFFIOT̃, Heleieth. Gênero, patriarcado, violência. São Paulo: Expressão Popular, 2015.

SILVA, Renata Silveira da. o tempo discursivo na Constituição do Imaginário do Trabalhador do Discurso da CUT. Tese de Doutorado. Pelotas: Universidade Católica de Pelotas, 2010. 